\title{
The Arnold Berliner Award 2013
}

\author{
Sven Thatje
}

Received: 23 May 2013 / Accepted: 23 May 2013 / Published online: 6 June 2013

(C) Springer-Verlag Berlin Heidelberg 2013

The Arnold Berliner Award is presented for the first time this year, as part of the 100-year birthday celebration of Naturwissenschaften (Fig. 1, Thatje 2013). It is my great pleasure to announce the first recipient of the award, Dr Mark Young (University of Edinburgh), in this editorial.

Mark Young (Fig. 2) was nominated for his work on the iconic Diplodocus, which, as a sauropod dinosaur, belonged to the largest terrestrial herbivores to ever have roamed Earth. Their pure size may have pushed them to the evolutionary limits of vertebrate biomechanics. In his paper published in Naturwissenschaften (Young et al. 2012), Mark and his colleagues presented a compelling multidisciplinary approach demonstrating that the gigantic Diplodocus was unlikely to have employed its bizarre dentition for a previously suggested bark-stripping hypothesis feeding strategy, and that the rather unusual (aberrant) dentition of Diplodocus may have, instead, demonstrated an adaptation for food procurement rather than an adaptation to high mechanical bite force. This would suggest that Diplodocus had a skull which was seemingly over-engineered for muscle-driven biting alone; the reason for which may have been related to other behavioral or ecological traits. This paradigmchanging discovery was only possible by making use of

\section{S. Thatje $(\triangle)$}

University of Southampton, Ocean and Earth Science,

National Oceanography Centre Southampton,

Southampton, SO14 3ZH, UK

e-mail: svth@noc.soton.ac.uk modern technology, the computed tomographic scanning of a fossil specimen of a Diplodocus longus skull from museum collection, and subsequent modeling of its biomechanics of feeding.

The Arnold Berliner Award was established in recognition of the founding editor of the journal. The award is sponsored by Springer Science+Business Media and is given annually for the best research article published in NAWI during the previous calendar year (Thatje 2012). Criteria are excellence in science, originality, and in particular interdisciplinarity,

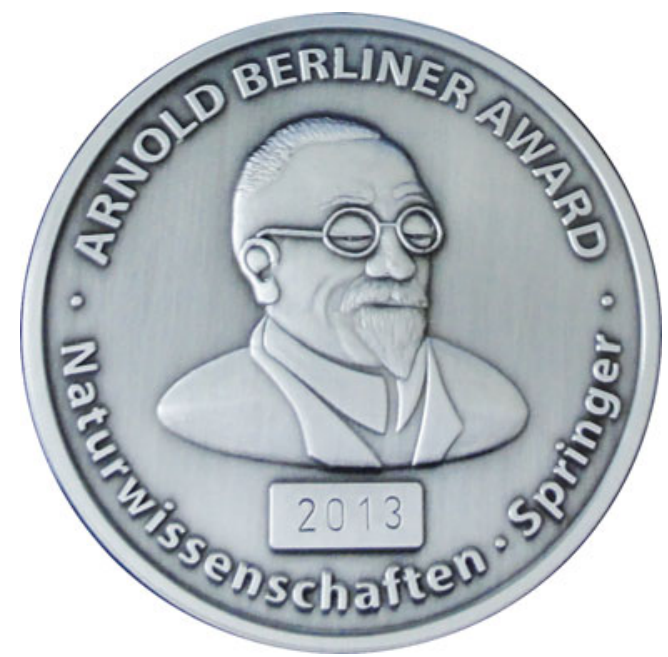

Fig. 1 The Arnold Berliner Award Medal. Arnold Berliner (18621942) was the founding editor of Naturwissenschaften and the journal's Editor-in-Chief from 1913 to 1935 


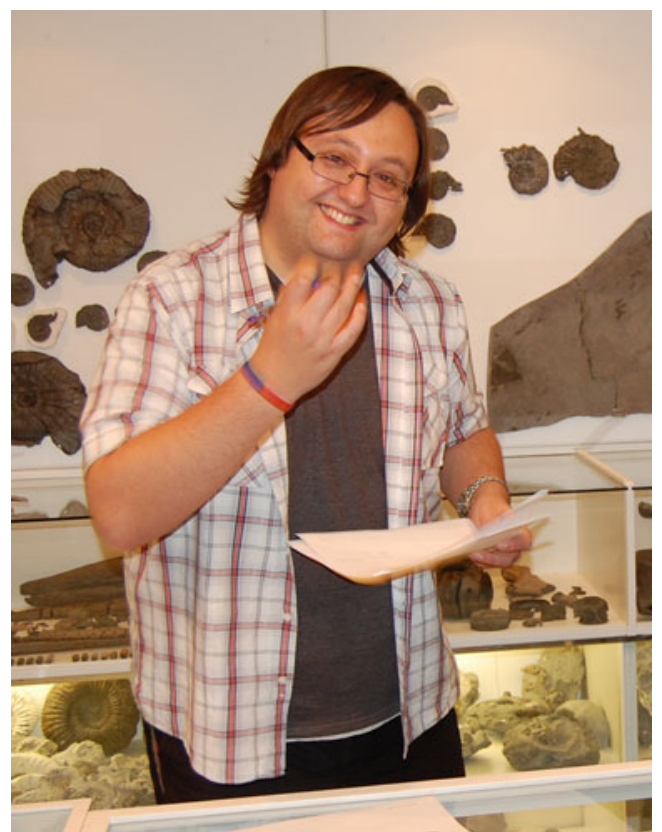

Fig. 2 Mark Young, Arnold Berliner Awardee 2013, assessing a fossil specimen overall mirroring Berliner's motivation for initiating NAWI. A jury, consisting of the board of editors and the Editor-in-Chief, selects the awardee. The Award is marked with the Arnold Berliner Medal (Fig. 1) and is accompanied by a biennial subscription to the electronic edition of Naturwissenschaften, a 500-Euro voucher for Springer books, as well as a cash prize of 250 Euros.

\section{References}

Thatje S (2012) Introducing the Arnold Berliner Award. Naturwissenschaften 99(9):675-676

Thatje S (2013) Celebrating 100 years: happy birthday, Naturwissenschaften! Naturwissenschaften 100:1

Young MT, Rayfield EJ, Holliday CM, Witmer LM, Button DJ, Upchurch P, Barrett PM (2012) Cranial biomechanics of Diplodocus (Dinosauria, Sauropoda): testing hypotheses of feeding behaviour in an extinct megaherbivore. Naturwissenschaften 99(8):637-643 